\title{
O papel da Igreja nos primórdios da educação dos surdos
}

\author{
Lucia Reily \\ Universidade Estadual de Campinas, Faculdade de Ciências Médicas \\ Centro de Estudos e Pesquisas em Reabilitação Prof. Dr. Gabriel Porto
}

\section{Introdução}

A temática da língua de sinais e seu papel na educação do aluno surdo é de uma amplitude extraordinária e mobiliza discussões polêmicas relacionadas a aspectos como as abordagens de educação do aluno surdo (oralismo, comunicação total, bimodalismo, bilingüismo, por exemplo), a constituição de uma "cultura surda", bem como as lutas de grupos minoritários por direitos lingüísticos, educacionais e políticos.

Como recorte no presente texto, procurei elucidar questões históricas sobre a origem da língua de sinais, o papel da Igreja monástica na invenção do alfabeto manual e os diferentes usos dos sinais monásticos pelos religiosos e da língua de sinais pelos surdos. Pretendo reconstruir uma narrativa fragmentada sobre o papel dos religiosos na educação dos surdos, que aproveitaram sinais manuais criados nos mosteiros com nova finalidade, visando a uma aplicação pedagógica.

Diferentemente da educação dos deficientes mentais, que, na Europa e posteriormente na América, teve origem no âmbito da medicina, em que tais pessoas compartilhavam espaços asilares segregados com doentes mentais desde o século XVII, a educação do surdo constituiu-se dentro do contexto religioso. Sem dúvida, as marcas do enfoque médico na educação do deficiente mental e da base monástica na educação do surdo coloriram as trajetórias históricas dessas duas frentes. Evidenciaram-se durante todo o século XX na ênfase no diagnóstico psicométrico no caso dos deficientes mentais e na prevalência de ações missionárias para os surdos, com publicação de manuais de língua de sinais de várias denominações cristãs (Igreja católica, Igreja do Nazareno, Igreja batista, entre outros), como mostra Sofiato (2005). Entre outras contribuições, procurei investigar a origem monástica do alfabeto manual utilizado até hoje no Brasil entre os surdos como complemento da Língua Brasileira de Sinais (Libras), sendo um recurso importantíssimo na escola regular durante o processo de letramento do aluno surdo no contexto da inclusão.

É preciso preencher lacunas e corrigir alguns equívocos ainda disseminados em textos atuais no campo da educação especial que buscam fornecer uma síntese histórica sobre a educação dos surdos. Temos 
orientado diversas monografias e dissertações de mestrado em que a fragilidade histórica sobre os primórdios da língua de sinais se evidenciou, daí a necessidade de buscar as conexões que faltavam na literatura brasileira sobre a história da educação do surdo. Em virtude da escassez de literatura histórica no país e da falta de acesso a documentos primários no Brasil, foram perdidos alguns elos importantes na narrativa histórica dos primórdios da educação dos surdos, os quais procuramos reconstituir e, em alguns casos, deduzir.

O leitor que consulta literatura sobre estudos de surdos defronta-se continuamente com algumas afirmações simplistas reproduzidas em textos acadêmicos, sem crítica ou questionamento. Listam-se ocorrências de forma desconexa, como as que seguem:

1. nos mosteiros medievais, a língua de sinais era utilizada para driblar o voto do silêncio;

2. o pioneiro na educação dos surdos foi o frade Pedro Ponce de León, que trabalhou com filhos da nobreza espanhola no século XVI;

3. a primeira publicação contendo o alfabeto manual é de autoria de Juan Pablo Bonet, outro espanhol, de 1620;

4. o primeiro educador a valorizar a língua de sinais foi o abade Charles Michel de l'Épée, que aprendeu sinais com grupos de surdos que vagavam pelas ruas de Paris.

Tal sequiência não elucida satisfatoriamente diversos aspectos necessários para que se tenha uma noção coerente sobre a contribuição dos religiosos na propagação da língua de sinais. Para compreender as ligações entre a prática dos sinais monásticos no período medieval e o aproveitamento de sinais por religiosos dedicados ao ensino de surdos no período do Iluminismo em vários Estados europeus, é preciso entender qual o sentido do voto do silêncio e até quando essa prática perdurou. Certamente também cabe refletir sobre as diferenças na prática dos sinais em comunidades de monges ouvintes e na comunidade surda. Neste estudo procuramos entender como ocor- reu o processo de apropriação da língua de sinais pelo abade de l'Épée. Ele teve contato com a língua de sinais utilizada nos mosteiros? A língua de sinais dos surdos de Paris tinha raízes nos sinais dos monges medievais? Como o alfabeto manual publicado por Bonet em 1620 na Espanha chegou até o abade de l'Épée em meados do século XVIII, na França?

Em razão da produção de conhecimento em diversas áreas, atualmente temos acesso a textos antigos, registros de acontecimentos e idéias não disponíveis há poucos anos, os quais nos permitem reconstruir um percurso histórico internacional. Entre os fatores que contribuíram para a divulgação de registros históricos importantes para a construção de uma narrativa coerente sobre o assunto temos:

1. o movimento da própria comunidade surda em busca de raízes históricas dos modos de educação do surdo (ver Eriksson, 1993);

2. o interesse da lingüística pelos temas de aquisição de linguagem (e da não-aquisição de linguagem), do bilingüismo; do ensino de segunda língua, entre outros;

3. pesquisas sobre tentativas de criar uma língua universal durante o Iluminismo (Eco, 2001);

4. a tecnologia de acesso a fac-símiles e arquivos históricos on-line em bibliotecas internacionais.

Além de investigar os processos de migração dos sistemas de sinais monásticos aos espaços de escolarização do surdo, este texto necessariamente aborda fundamentos sobre a prática sígnica em si, ou seja, aborda os sinais manuais como sistema, na especificidade das possibilidades de registro e disseminação, pois as linguagens espaço-gestuais escapam ao registro gráfico, como veremos. A natureza efêmera do gesto traz conseqüências para a sua transmissão no espaço e no tempo e para a sua apropriação pelo professor da rede regular de ensino que desconhece a língua de sinais e se vê diante do desafio de educar um aluno surdo. Daí a importância de compreender a di- 
mensão histórica da origem dos sinais monásticos e dos esforços empreendidos historicamente para apropriar-se desse recurso essencial à educação do aluno surdo.

\section{A linguagem de sinais como instrumento dinâmico}

Antes de adentrar as questões específicas que mobilizaram este estudo, cabe explicitar que ele se fundamenta na abordagem sociocultural elaborada por Vygotsky (1988). Importam-nos especificamente seus preceitos sobre a prática humana de inventar instrumentos, tanto físicos quanto psicológicos, adaptados conforme as necessidades sociais que se colocam num dado momento para um grupo específico de pessoas, e sobre a linguagem como instrumento psicológico e social privilegiado, que permite constituir e transportar sentidos inter e intrapessoais.

Para James Wertsch (1991), autor americano estudioso e divulgador das idéias de Vygotsky e outros teóricos da escola soviética, Vygotsky poderia ter avançado ainda mais com sua analogia sobre a ferramenta psicológica, no sentido de que cada ferramenta é projetada tendo em vista uma finalidade específica. Da mesma forma, cada sistema lingüístico foi projetado

[...] para responder a uma demanda bastante específica, porque a situação dita o recurso que é necessário. Assim, o homem inventou as linguagens - sistemas de representação criados conforme a necessidade que se mostrava presente. Sistemas verbais, com estruturação bastante complexa e convencionalizada, como as línguas faladas ou as línguas de sinais; sistemas não-verbais, igualmente complexos mas mais polissêmicos, como a música e o desenho. A modalidade lingüística será visual, sonora, corporal, gráfica ou até digital - isso vai depender de quem está significando o que para quem, por quais razões, e em quais circunstâncias. (Reily, 2004, p. 18)

Toda vez que ocorrem obstáculos para utilização da língua falada, seja na emissão ou na compreen- são, seja diante da necessidade de manter sigilo ou por restrições profissionais, a linguagem reconfigurase conforme a modalidade que melhor se adapta àquelas circunstâncias e possibilidades.

Segundo Umiker-Sebeok e Sebeok (1987), sistemas sinalizados têm sido criados

1. para viabilizar comunicação à distância, por profissionais como acrobatas, atletas, leiloeiros, marinheiros, motoristas de caminhão e topógrafos, entre outros;

2. para possibilitar comunicação em espaços com alto nível de ruído, por bombeiros, mecânicos, profissionais de aviação, de serrarias, da bolsa de valores etc.;

3. quando é preciso transmitir informações sigilosas, por atletas, criminosos, militares, escoteiros, por exemplo;

4. pela necessidade de manter silêncio, por regentes de orquestra, mergulhadores, religiosos de mosteiros.

Os sistemas sígnicos utilizados para as necessidades exemplificadas configuram-se como modalidades lingüísticas espaço-gestuais; trata-se de alternativas dependentes da sua base na linguagem oral. Ou seja: esses sistemas codificados, convencionalizados, não se sustentam independentemente da língua.

Adam Kendon (apud Umiker-Sebeok e Sebeok, 1987) diferencia duas modalidades distintas de linguagens de sinais no verbete de sua autoria que consta da International Encyclopedia of Communications: as línguas de sinais primárias e as linguagens de sinais alternativas. As línguas de sinais primárias "servem como meio principal de comunicação para um grupo de sinalizadores, e não como uma alternativa à língua falada"1 ("Prefácio", p. x, tradução minha). As

${ }^{1}$ Libras, American Sign Language (ASL) e Langue de Signes Française (LSF) são exemplos de línguas de sinais usadas por comunidades surdas do Brasil, dos Estados Unidos e da França, respectivamente. 
alternativas, por sua vez, são "linguagens de sinais desenvolvidas por falantes ouvintes para uso em ocasiões especiais ou durante períodos em que a fala não é permitida em razão de rituais ou por dificuldades circunstanciais" (idem). Kendon criou uma classificação destacando linguagens sinalizadas por grupos étnicos (como as linguagens sinalizadas de índios norte-americanos ${ }^{2}$ ); sistemas de sinais ocupacionais, citados anteriormente; linguagens sinalizadas de apresentações artísticas ou de rituais performáticos; sinais monásticos.

\section{O desafio histórico de representar os sinais manuais graficamente}

A linguagem é dinâmica e constitui-se na interação social, com funções diversas dependendo dos propósitos dos usuários e do contexto. Os sistemas de sinais gestuais são igualmente dinâmicos. Convencionalizam-se e firmam-se como sistemas, mas podem mudar para atender às demandas sociais que se vão apresentando. Em virtude de sua natureza efêmera, têm desafiado inúmeros interessados em fixá-los, representá-los (desenhando ou descrevendo em escrita) e registrá-los. Diferentemente da linguagem oral que foi, de certa forma, domada pela invenção da escrita, Rée (2000) considera que ainda não foi inventado para as linguagens de sinais um sistema eficiente de representação gráfica que permita a sua reprodução em espaços ou tempos distantes. ${ }^{3}$ E não foram poucas as tentativas, sendo que o primeiro esforço registrado de que se tem notícia data da Idade Média, como veremos adiante. Com objetivos instru-

${ }^{2} \mathrm{O}$ leitor interessado em aprofundar seus conhecimentos sobre a linguagem sinalizada dos índios norte-americanos poderá consultar Tomkins (1969) e Mallery (2001).

${ }^{3}$ Há pesquisadores trabalhando com um sistema denominado sign writing como solução promissora para a leitura e escrita de sinais, mas não existem ainda resultados de pesquisa convincentes que mostrem que essa solução poderá configurar-se como um modo de representação eficiente e funcional. cionais ou missionários, vários inventores viram seus esforços frustrados diante da dificuldade de captar a tridimensionalidade, o movimento, a expressividade dos sinais e sujeitá-los a um sistema de representação gráfica compreensível.

Por conta do fato de que não existem até então soluções bem-sucedidas e transparentes para a representação dos sinais espaço-gestuais, eles têm-se perdido no tempo. Sobreviveram melhor alguns dos antigos alfabetos manuais, que foram desenhados, copiados, gravados e em alguns casos publicados. Se não fosse pelo fato de que os sinais monásticos continuam em uso em algumas comunidades cistercienses e trapistas hoje (mesmo que correndo risco de extinção), seria difícil recuperar os movimentos representados pelas descrições verbais das listagens preservadas.

Por que conseguimos reproduzir alguns conjuntos de sinais de alfabetos manuais criados na Idade Média, mas temos maior dificuldade em realizar as configurações manuais e os movimentos de palavras inteiras utilizados na mesma época? Sofiato (2005), em sua dissertação de mestrado, oferece algumas pistas para responder a essa questão ao avaliar manuais e dicionários de língua de sinais quanto às estratégias de desenhar ou fotografar os movimentos manuais e a expressão facial e corporal que compõem alguns sinais. No entanto, essa questão merece maior aprofundamento do que pretendemos dispensar no presente trabalho. Mais do que realizar um estudo histórico sobre os modos de representar os sinais, o foco deste trabalho é a prática dos sinais pelos religiosos e a investigação de como os sinais monásticos migraram para o contexto da educação dos surdos.

\section{O que sabemos sobre a constituição dos sinais monásticos?}

Minha tentativa de reconstruir a narrativa iniciase com uma síntese sobre a prática dos sinais nos mosteiros medievais.

A criação do monasticismo data do período de Santo Antão e São Pacômio, fundadores respectiva- 
mente da forma solitária (para eremitas) e comunitária (mosteiros), no Egito, no final do século III e começo do século IV (Walker, 1985); portanto, a origem dos mosteiros foi oriental. Reily (1997) ${ }^{4}$ interpreta o movimento monástico como sendo um novo tipo de martírio que surgiu após a legalização do cristianismo por Constantino no Império Romano em 313. Viver nos mosteiros no século IV d.C. significava assumir uma nova forma de heroísmo cristão, já que os fiéis não estavam mais sendo jogados aos leões pelos romanos. Para os devotos, o martírio traduzia-se simbolicamente em graça pelos pecados cometidos, pavimentando o caminho da salvação. Depois que a fé cristã passou a ser reconhecida no Império Romano, fechou-se um espaço de penitência que era visto como caminho para a glória. Uma alternativa auto-imposta equivalente precisou ser criada, com outras formas de sofrimento: o isolamento social, a vida asceta, a castidade, o jejum, o trabalho árduo e, ainda, o silêncio. Nos mosteiros, os devotos buscavam viver em isolamento, imitando a prática dos santos eremitas do deserto egípcio, buscando a perfeição por meio da oração e do jejum.

O isolamento e a vida monástica configuravamse como um espaço de penitência. Apesar das duras exigências, o número de mosteiros cresceu muito rapidamente, refletindo que as condições de vida no sistema feudal fora dos mosteiros também eram extremamente difíceis para a população laica.

O movimento monástico alastrou-se também para o Ocidente, sendo que um dos grandes promotores no Ocidente foi São Jerônimo, que finalizou em 384 d.C. a tradução da Bíblia do hebraico e do grego para o latim, conhecida como Vulgata. Assim, ao longo do tempo, constituíram-se duas grandes formas de cristianismo: a Oriental, centrada em Constantinopla - a Igreja Ortodoxa; e a Ocidental, em Roma - a Igreja Romana.

${ }^{4}$ Os fundamentos históricos sobre o movimento monástico foram escritos em colaboração com Duncan Alexander Reily, meu pai, quando este trabalho foi apresentado, numa versão anterior, na $26^{\text {a }}$ Reunião Anual da ANPEd (ver Reily e Reily, 2003).
Desenvolveram-se, então, duas formas típicas de monasticismo (Bainton, 1966):

1. a oriental, seguindo as Regras Monásticas de São Basílio (c. 330-379 d.C.);

2. a ocidental, que seguia as Regras de São Bento (baseadas nas Regras de São Basílio) (c. 480550 d.C.).

As comunidades monásticas eram auto-suficientes, e por isso acolhiam não apenas noviços mas também artesãos e trabalhadores capacitados em toda esfera necessária para a sobrevivência básica, dentro dos padrões de simplicidade daquela opção de vida. À medida que os mosteiros cresciam, foi preciso estabelecer regras de convivência e trabalho, já que no início os agrupamentos se localizavam em áreas distantes e inacessíveis, muitas vezes inóspitas. Os dois movimentos monásticos (oriental e ocidental) seguiam regras que instituíam o voto do silêncio, coerente com os objetivos de promover a oração e reflexão (Walker, 1985).

\section{A vida monástica e a prática do silêncio}

Nos mosteiros das ordens beneditinas (ocidentais), os noviços faziam três votos primordiais: pobreza, castidade e obediência. Além desses, assumiam também o voto da estabilidade, que determinava a permanência na mesma comunidade monástica durante toda a vida; não era permitida a peregrinação de um mosteiro a outro na busca de um espaço com melhores condições de vida. Alguns mosteiros instituíram o voto do silêncio como prática cotidiana. $\mathrm{O}$ silêncio no período monástico, segundo regras estabelecidas por São Basílio Magno (Igreja oriental) no século IV d.C., era determinado para os noviços com o objetivo de levá-los a desvestirem-se dos costumes anteriores, purificando-se no silêncio para aprender uma nova maneira de viver. Entendia-se que o contato com o mundano contaminava a alma, e o silêncio tinha a função de apagar as lembranças da vida pregressa, como se vê no texto da regra. 
É bom para os noviços também a prática do silêncio. Se dominam a língua, darão simultaneamente boa prova de temperança. Com o silêncio aprenderão junto dos que sabem usar da palavra, com concisão e firmeza, como convém perguntar e responder a cada um. Há um tom de voz, uma palavra comedida, um tempo oportuno, uma propriedade no falar, peculiares e adequados aos que praticam a piedade. Não os aprende quem não tiver abandonado aquilo a que estiver acostumado. O silêncio traz consigo o esquecimento da vida anterior, em conseqüência da interrupção, e proporciona lazer para o aprendizado do bem.

Assim, a não ser por questão especial atinente ao bem da própria alma, ou por inevitável necessidade de um trabalho em mãos, ou por negócio urgente, guarde-se o silêncio, excetuada é claro, a salmodia. (São Basílio Magno, 1983, p. 70)

Igualmente, os mosteiros que seguiam a Regra de São Bento também respeitavam o silêncio (Banham, 1991). Consta no capítulo 6 da Regra de São Bento:

\section{DO PERMANECER SILENCIOSO}

Façamos o que diz o Profeta: "Eu disse, guardarei os meus caminhos, a fim de não pecar pela língua; pus uma guarda em minha boca, fiquei mudo, humilde e permaneci calado, mesmo quanto às coisas boas". Nesse lugar o Profeta mostra que, se convém ficar calado de vez em quando, mesmo em relação às coisas boas, por causa do valor do silêncio, quanto mais devemos parar de falar palavras más, por causa do castigo do pecado.

Por isso, ainda que se trate de conversas boas, santas e edificantes, conceda-se apenas raramente aos discípulos perfeitos a licença de falar, por causa da importância do silêncio. Porque está escrito: "o muito falar não fugirás ao pecado" e noutro lugar: "A morte e a vida estão submetidas ao poder da língua”. Com efeito, falar e ensinar pertencem ao mestre; calar e ouvir convêm ao discípulo.

Assim sendo, se for preciso pedir alguma coisa ao superior, que se peça com toda humildade, submissão e reverência. Porém, as brincadeiras, as palavras à-toa e as que provocam riso, nós as proibimos em todo lugar e para sempre, nem permitiremos ao discípulo abrir a boca para tais palavras. (São Bento, 1993, p. 29)

\section{A criação de sinais monásticos e de alfabetos manuais}

Tanto as regras de São Basílio quanto as regras de São Bento sugerem que o silêncio reinava durante as atividades laborais cotidianas, mas não durante as oito horas (Vigília, Matinas ou Laudas, Prima, Terça, Sexta, Noa, Vésperas, Completas), ${ }^{5}$ cultos de louvor que ocupavam boa parte do dia monástico. Além de meditação e oração, os mosteiros também eram espaços de trabalho, e por isso surgiu uma comunicação silenciosa entre os monges, necessária para o desempenho das várias atividades para subsistência de todos; constituiu-se uma linguagem de sinais manuais.

Linguagens sinalizadas foram incorporadas oficialmente nas práticas monásticas, segundo Banham (1991), e buscaram-se formas de transmissão dos sinais, intra e intermosteiros, por meio de registros instrucionais. Intramosteiro porque os noviços que chegavam precisavam aprender; e extramosteiro para dar apoio a novos agrupamentos e manter coesão entre as comunidades da Igreja. ${ }^{6} \mathrm{Um}$ dos mais antigos documentos preservados (provavelmente copiado entre 910

${ }^{5}$ Sintetizamos o horário do louvor, conforme descrição detalhada de Ó Conbhuidhe (1999) sobre as práticas das abadias cistercienses da Irlanda: Vigília (início dos ofícios litúrgicos, cerca de duas horas depois da meia noite), Matinas ou Laudas (salmodia ao nascer do sol), Prima (salmodia em plena luz da manhã, seguida de explicações sobre a regra para os monges e noviços e em certos dias, admissão pública de faltas contra a Regra); Terça (após os trabalhos da manhã, a salmodia era seguida da missa tradicional); Sexta (canto anterior ao almoço ao meiodia), Noa (salmodia às 14:00, aproximadamente); Vésperas (ao final da tarde, seguida de leitura de devocional para reflexão da comunidade reunida), Completas (oração final antes do repouso da noite).

${ }^{6}$ Van Rijnberk (1987) propõe que um objetivo secundário dos sinais monásticos poderia ter sido a comunicação dos religiosos em países estrangeiros, cuja língua desconheciam, já que no início havia pouca diferenciação no léxico e nos modos de realizar os sinais. A diversidade foi se constituindo aos poucos. 
e 1000 d.C., segundo a organizadora da edição), em inglês arcaico, da ordem beneditina, é denominado Monasteriales Indicia. Esse documento, produzido nas Ilhas Britânicas, não pereceu, diferentemente de outros manuscritos dos mosteiros do continente. Houve grande incidência de perda e destruição de registros e documentos das ordens religiosas, resultado de saques, guerras civis e perseguições religiosas durante a Alta Idade Média e o Renascimento (Reforma e Contra-Reforma) e em virtude da dissolução dos mosteiros na Inglaterra e na Irlanda (O Conbhuidhe, 1999), e posteriormente por conta da Inquisição e de invasões que afetaram drasticamente a Espanha e Portugal (Plann, 1997; Daniels, 1997).

Não se sabe o quanto o voto do silêncio era de fato respeitado nos vários mosteiros; segundo Banham (1991), também não há registros sobre como se dava a prática da comunicação com as mãos nos mosteiros. Vários desafios se apresentavam para a difusão de uma linguagem sinalizada única para os vários centros monásticos, entre os quais citamos o esforço para copiar os textos manualmente em pergaminho, bem como a fragilidade desse material e seu alto custo. Além disso, existia a dificuldade até hoje não resolvida de realização dos sinais manuais a partir de descrições verbais, mesmo quando acompanhadas de ilustrações. A Monasteriales Indicia traz 127 sinais descritos verbalmente, sendo que a edição de Banham inclui cinco desenhos baseados nas ilustrações medievais que compunham o texto, que facilitam a interpretação do gesto pretendido quando se conhece o objeto ou ação a que se refere o sinal. Não inclui, no entanto, nenhuma indicação sobre o alfabeto manual.

Como alguns dos manuscritos preservados de alfabetos manuais e listas de sinais eram de outras ordens religiosas que não a beneditina, é importante recordar que, na virada do primeiro milênio, houve diversas "reformas" monásticas, sendo as duas mais importantes a de Cluny, em 910, e a cisterciense (iniciada em 1098, em Cîteaux), ambas da linha do monasticismo beneditino. Embora não caiba aqui aprofundar seus motivos, em síntese a reforma de
Cluny revelava o crescente envolvimento dos monges com a sociedade, buscando o fim das disputas feudais, ao passo que a reforma cisterciense pretendeu retomar os ideais monásticos de estrita observância da regra instituída por São Bento (Bainton, 1966). Por ocasião dessas reformas, foram produzidas as várias listagens de sinais mencionadas adiante; presumese que a intenção desse registro tenha sido valorizar e divulgar a prática da comunicação silenciosa, e não apenas documentar esse modo de comunicação para a posteridade.

\section{Os alfabetos manuais dos monges}

Pelo que pudemos deduzir, os alfabetos manuais monásticos foram uma criação independente das listagens de sinais; nenhuma das listagens a que tivemos acesso contém configurações manuais para o alfabeto. Considerando o papel dos mosteiros da Idade Média como centros de cópias de livros clássicos e religiosos, alguns decorados de iluminuras, faz muito sentido que os monges que usavam sinais para se comunicarem silenciosamente no trabalho do campo também tivessem necessidade de criar sinais para as letras do alfabeto, a fim de que os escribas pudessem conferir suas cópias no contexto do scriptorium. A listagem de sinais do Monasteriales Indicia oferecenos alguma indicação sobre a importância do texto escrito para a vida dos monges beneditinos. Quase dez por cento dos sinais referem-se a textos, a maioria de natureza religiosa. Nas palavras de Martins, que estudou as listas cistercienses portuguesas:

Os Livros de Sinais valem também como documentos da vida monacal. Vemos falar os monges. E a gesticular eles são capazes de nomear muitas coisas, por exemplo, os livros do convento: o livro misal, o livro da epistola, o livro do evãgelho, o livro colector, o livro $1 / 2$, , que se lee aos nocturnos, o livro das antifãns, o livro do respõso, o livro da regra, o livro dos usos (e há muitos, entre os códices de Alcabaça), o livro psalteiro - enfim, quase uma pequena biblioteca. Ou então, como reza o segundo Livro de Sinais: o liçoeiro, o responsório, o antiphoneyro, o hymnorio, o 
collectaneo, o psalteyro, a brivia, o missal, o pistoleyro e evangeliorum..$^{7}(1987$, p. 549)

Além desses, havia nos mosteiros textos referentes a aspectos administrativos da comunidade, como documentos de contabilidade, escrituras de terras doadas e correspondências da igreja. Livros para estudo religioso, escritos dos santos padres, as vidas dos santos - todo tipo de texto tinha de ser copiado manualmente em pergaminho (já que o papiro que se utilizara anteriormente não resistia ao tempo nas regiões mais úmidas dos países europeus). Ao propor um trabalho de formação de leitores, também se tornava necessário montar uma biblioteca de clássicos para ensino de grego e latim, gramática e o vernáculo (Graham, 1923).

A comunidade surda internacional tem investido na pesquisa sobre as raízes da língua de sinais e dos alfabetos manuais, traçando sua disseminação pelo Ocidente. Um trabalho didático e amplamente ilustrado foi publicado por Eriksson (1993), contendo uma listagem de manuscritos e publicações, alguns com figuras, produzidos por religiosos a partir da Idade Média.

A obra mais antiga de que se tem notícia foi escrita pelo historiador eclesiástico inglês Venerável Bede (672-735), autor do renomado livro The ecclesiastical history of the English Nation and the lives of St. Cuthbert \& the Abbots (c. 731). O monge registrou um sistema de numerais romanos representados em desenhos de configurações manuais em De computo

${ }^{7} \mathrm{O}$ livro misal refere-se ao texto contendo a liturgia da missa; o livro da epistola traz as cartas do apóstolo São Paulo; o livro do evãgelho indica os livros dos quatro evangelistas do Novo Testamento (Mateus, Marcos, Lucas e João); o livro 1/2,, que se lee aos nocturnos refere-se, supomos, ao devocional; o livro das antifãns é o hinário e o livro do respõso é um texto litúrgico; o livro da regra remete à Regra de São Bento; o livro dos usos trata das práticas do cotidiano, inferimos; o livro psalteiro indica o livro de Salmos de Davi; o hymnorio indica o livro de hinos e a brivia é um livro de orações. vel loquela digitorum. Sua proposta era utilizar as mesmas configurações para significar letras. Trata-se de um sistema de origem oriental arcaica com lógica interna, no qual os componentes ganham significado pela relação mútua de oposição ou exclusão. Para contar de 1 a 9 mil, as mãos permanecem em posição neutra diante do corpo. De 10 mil até 1 milhão, entra o movimento, e a localização das mãos diante do corpo altera-se: a posição da mão desce do tórax até a coxa, indicando aumento do valor. Não seria possível assimilar os sentidos desse sistema sem passar por um processo de aprendizagem deliberada, explica Barley (1987).

Outra tentativa criativa foi a associação de letras a partes do corpo humano, registrada na obra $D e$ Furtivis Literarum Notis pelo italiano Giovanni Battista della Porta (1535-c. 1610). Publicado em 1563, esse volume traz as seguintes associações: Auris $($ orelha $)=\mathrm{A} ;$ Barba $=\mathrm{B} ;$ Caput $($ cabeça $)=\mathrm{C}$; Dentes $=\mathrm{D}$, e assim por diante. Por ser um sistema mnemônico, seria fácil relacionar as letras a nomes de partes da anatomia; no entanto, a idéia foi abandonada. Além da dificuldade de encontrar palavras adequadas para cada parte do corpo, e do fato de a proposta requerer uma movimentação pouco econômica, Eriksson (1993) sugeriu que a idéia fracassou porque os religiosos desencorajavam a atenção explícita à carne. Pelo que se sabe, esse código nunca foi utilizado na educação dos surdos.

Segundo Eriksson (1993), os religiosos dos países do sul da Europa valorizaram a aprendizagem do alfabeto manual nos mosteiros para as necessidades de comunicação e confissão de pacientes enfermos e moribundos. Para divulgar os sinais entre os religiosos, o frei franciscano espanhol Melchior de Yebra (1526-1586) produziu a pequena obra Refugium Informorum, por el Padre Fray Melchior de Yebra (“Consolo para os enfermos"), publicado postumamente em Madri no ano de 1593. A obra contém seis páginas de ilustrações de configurações manuais, muitas das quais são parecidas com as grafias das letras. O livro era ilustrado com as posições do alfabeto manual, seguindo o alfabeto de São Boaventura, con- 
tendo uma coleção de aforismos para orientar a conduta cristã, cada qual iniciada por uma letra do alfabeto (Daniels, 1997). A importância dessa obra é o fato de as configurações manuais do alfabeto manual publicado por Yebra ser o mesmo posteriormente publicado por Juan Pablo Bonet em 1620, mesmo que este não cite a fonte, levantando suspeitas entre os autores (Moores, 1987; Daniels, 1997; Plann, 1997; Rée, 2000) sobre a ocorrência de plágio.

Cosmas Rosselius, monge franciscano de Florença, produziu ainda o Thesaurus Artificiosae Memororiae, de publicação póstuma em 1679, contendo cinco pranchas ilustradas que mostravam três variações de alfabetos unimanuais. Nas três versões, é evidente a tentativa de criar configurações manuais parecidas com as letras gráficas.

\section{As listagens de sinais monásticos}

O fato de que sobreviveram diversas versões dos sinais monásticos atesta que essa prática se consolidou e se alastrou no espaço e no tempo. Segundo Banham (1991), ao compará-las, fica evidente que a base dos sinais é comum, embora os documentos continentais revelem que a vida talvez fosse menos austera, já que o léxico para os alimentos é mais variado, refletindo diferenças nos modos de vida. Van Rijnberk (1987) lista 20 índices monásticos, enquanto a publicação de Umiker-Sebeok e Sebeok (1987) reuniu 14 listagens em latim e no vernáculo; a maioria é arcaica, mas algumas estão em uso hoje em mosteiros cistercienses e trapistas. Entre elas encontramos:

- De Notitia Signorum - de Bernard de Cluny (listagem em latim da Ordem de Cluny, produzida até meados do século XI com 296 sinais);

- De Silentio - de William de Hirsau (listagem produzida antes de 1089 que complementa o Notitia Signorum, com 365 sinais);

- Ars Signorum Cisterciensium - listagem em latim do Mosteiro de Cîteaux, publicado no século XVI (com 225 sinais);
- A Table of Signs Used During the Hours of Silence - lista da Ordem de Santa Brígida, do Mosteiro de Sion em Isleworth em Middlesex, na Inglaterra, de meados do século XV, aproximadamente (com 106 sinais em ordem alfabética);

- I "Signa Loquendi" Cisterciensi - sinais da Espanha, de meados do século XV, aproximadamente (com 287 sinais);

- Livro de Sinais de Alcobaça 218 - lista cisterciense em português, do Mosteiro de Alcobaça, de meados do século XV, aproximadamente (com 198 sinais organizados por categorias);

- Livro de Sinais Cód. Alc. 91 - lista cisterciense em português, do Mosteiro de Braga, datado de 1547 (com 226 sinais organizados por categorias);

- Vocabulaire des Signes Pratiqués dans l'Ordre de Cîteaux - lista em francês, sem data, praticada desde a Reforma dos Trapistas (com 167 sinais em ordem alfabética);

- Authorized list of signs for the Cistercian Order - basic signs - versão traduzida do francês em 1926, utilizada em Dublin (com 229 sinais).

Para ter uma noção dos modos de descrever os sinais, vejamos exemplos comparativos para o item "pão" de algumas listagens apresentadas no volume editado por Umiker-Sebeok e Sebeok (1987).

- “PANIS: 59 Cum duplex pollex quase spera sic sociatur, 60 - Et duplex index, sic panis signficatur (Ars Signorum Cisterciensium)". (Umiker-Sebeok \& Sebeok, 1987, p. 398)

- "88 Pan Por señal de pan junta las cabeças de los dedos \& de los dos primeros, \& así juntados faz cerco dellos (I 'Signa Loquendi' Cisterciensi)". (Penna, 1987, p. 513)

- "BREDE. Make with thy two thumbs and two forefyngers a roude coupas. And if thou wole haue White make the sign therof (of white) 
And if brown toche thy cowll sleue (A Table of Signs Used During the Hours of Silence)". (Bentley, 1987, p. 490)

- "58. signal de pam, faze signal co anbolos dedos polegares e com anbolos demonstradores (Livro de Sinais Cód. Alc. 218)". (Martins, 1987, p. 558)

- "Pain: Etendre deux doigts avec le pouce em triangle (Vocabulaire des Signes Pratiqués dans l'Ordre de Cîteaux)". (Du Bois, 1987, p. 610)

O estudo comparativo das listagens de sinais monásticos relacionadas requer, além de domínio do latim e de outras línguas, entre as quais o alemão, o holandês, o inglês, o francês, o espanhol e o português, nas suas formas arcaicas e atuais, também um conhecimento da vida monástica, dos alimentos, da economia e organização social, dos objetos e vestimentas litúrgicos, dos textos, das ferramentas utilizadas nos afazeres cotidianos.

Há diferenças nos livros de sinais das várias ordens e nas várias línguas. Mário Martins explica:

Não pensemos que todos os Livros de Sinais rezam sempre pela mesma cartilha, ainda quando eram do mesmo país ou usados em época igual. Noutros casos, coincidem, embora distanciados no tempo e no espaço. Por exemplo: no Livro de Sinais em latim, do cód. alc. 76, os monges, para designar leite, imitam o mungir duma vaca e o chuchar dum menino: "Signum lactis est pollice et indice trahere minimum digitum alterius manus, sicut vaca trahi solet". Ora, a imitação do bebé aparece também nas listas antigas do monge Bernardo, de Udalrico e do Mosteiro de S. Vítor de Paris. E a mímica de mungir a vaca vemo-la num convento do sul da Inglaterra, à volta do ano 1050, num manuscrito quatrocentista dumas freiras inglesas, na abadia de Hirsau, num códice de Namur e ainda noutros lugares.

Conclusão: algumas vezes os sinais fixavam-se definitivamente e vemo-los passar de códice para códice. Nou- tros, iam variando ao gosto dos seleccionadores. Esperamos que o leitor não nos obrigue a descrever os quatro costados de cada um dos nossos Livros de Sinais nem a traçar a sua árvore genealógica. (1987, p. 546-547)

Também há variações quanto ao grau de sofisticação lingüística nas várias listagens. Barley (1987) explica que o sistema de signos do Monasterialis Indicia, diferentemente dos gestos trapistas analisados por Hutt (1968), carece da complexidade sintática e das especificações de estado de humor das listagens mais trabalhadas.

\section{O uso de sinais entre os religiosos}

Os manuscritos monásticos que sobreviveram descortinam muito pouco sobre a vida cotidiana dos monges e suas relações com a comunidade do entorno; Banham (1991) explica que não sobraram relatos pessoais, como diários ou correspondências, revelando não os modos que os monges se deveriam portar, mas como de fato as interações se davam. As listas de sinais não elucidam como a comunicação acontecia, ou se os alfabetos manuais eram integrados na sinalização. Mas é possível inferir alguma coisa sobre as vivências no mosteiro pelo léxico preservado nas listas. Numa encantadora passagem, Martins descreve a imagem desenhada pelas palavras do Livro de Sinais Cisterciense traduzido no Mosteiro de Alcobaça: ${ }^{9}$

Graças a estes sinais, a vida monacal vai decorrendo diante de nós, como um rio lento e manso, na familiaridade dos gestos caseiros: os porteiros dão a volta à chave [...], os monges esfregam as mãos com frio [...], vestem corajosamente as bragas [...], apertam o cinto e sabem perfeitamente o que é um graal [...] e um saleiro [...]. De noite, levantamse e rezam os salmos à luz duma lanterna furta-fogo, chamada abscõsa [...].

Nos horizontes gastronômicos da cozinha e despensa, nas mesas amplas de refeitório, repoisavam as comidas

\footnotetext{
${ }^{9}$ Do Cód. Alc. 218 da Biblioteca Nacional de Lisboa.
} 
simples: pão, queijada, empada, vinho, vinagre, azeite, queijo, leite, mel, ovos e tudo o que servia de $p u l m^{1 / 2}$ to para os monges comerem com pão [...]. Vasto era o mundo das frutas e hortaliças pois os cistercienses amanhavam terras amplas e férteis: maçãs, cerejas, pêras, laranjas, porros, alhos, rábanos, favas, nozes, amêndoas, avelãs e pepinos. E para tudo havia sinais [...]. (1987, p. 549-550)

Martins (1987) descreve os sinais monásticos como sendo uma simples mímica, "filha engraçada de um deus mudo" (p. 547).

Quantos mártires tinham ganhado o céu com a cabeça cortada!? Por conseguinte, para significar mártir, os monges punham a mão na base da cabeça, à maneira dum cutelo, como se a fossem decepar [...]. Quem não viu bater ovos? Era imitando esta alegre função culinária que eles se nomeavam [...]. E o boi de retorcidos cornos, como dizia Homero? Não podia haver dúvidas: com gesto fácil, imitavam-se estes belos ornamentos na cabeça paciente dos monges [...]. E eles compreendiam logo: boi!

[...] Quem não andou atrás das enguias fugitivas, capazes de escapar às mãos mais obstinadas? É a imitar estes pescadores improvisados e aflitos que tanto os cluniacenses como os monges de Cister nos convidam: Por signal de antiga, aperta anballas mãaos asy como quẽ a tem $e$ scorrega [...]. Para designar enxada, também era simples: faze co as mãos curvas como quem cava [...]. (p. 547-548)

Às vezes, no entanto, o sentido original distanciase do gesto das ações familiares e esconde-se "à maneira dos caracteres recessivos da hereditariedade", explica Martins (p. 548). É o caso do sinal de mulher, "trazer o dedo demonstrador pella testa, de sobrancelha a sobrãcelha" (p. 556), representando a fita que as mulheres casadas usavam para segurar o cabelo.

Numa análise semiótica do sistema dos monges anglo-saxões, Barley (1987) elucida que os sentidos para nomear as funções eram representados por meio da mímica do aspecto mais chamativo da pessoa. Assim, o diácono era mostrado pelo gesto de balançar um sino, "num tipo de semiótica metonímica" (p. 60).
De outro modo, o emissor pode simbolicamente transformar parte de seu próprio corpo em objeto e agir sobre ele em mímica. Assim, "Se você quiser leite, então alise seu dedo esquerdo com sua mão direita como se você estivesse tirando leite". Em outras palavras, o leite se tornou a teta da vaca. Isso, então, é um tipo de semiótica metafórica. (p. 60)

Uma terceira forma semiótica de representação seria a icônica, na qual se desenha no corpo o objeto desejado. No sistema dos sinais monásticos, "os sinais reproduzem funções, formas, colocações reais" (p. 60), que são altamente associadas a seus referentes, diferentemente dos sinais de contagem do Venerável Bede, que são representações bastante arbitrárias.

Há também sinais compostos, nos quais, por exemplo, uma classe é indicada, e em seguida vem uma adição icônica, às vezes um qualificador para grande (erguer o polegar) ou pequeno (erguer o dedo mínimo). Por exemplo, no Monasterialis Indicia, o sinal completo para martirologia pequena (um livro sintético da vida dos santos mártires) é composto pelos sinais para livro, mártir e pequeno: "Quando quiser uma martirologia pequena, então movimente sua mão e coloque o indicador sobre a garganta e erga o dedo mínimo" (Banham, 1991, p. 31, tradução minha).

\section{Barley (1987) avisa que}

[...] haverá sempre uma brecha entre o sentido total SIGNIFICADO e o sentido total INTERPRETADO. É como se houvesse maior conteúdo sendo recebido do que de fato fora transmitido. A diferença, claro, é fornecida pelas estruturas cognitivas e pelo conhecimento efetivo do receptor. Como a maioria dos sinais com que estamos lidando são grandemente motivados externamente, esse elemento consiste principalmente em limitar o campo de aplicação dos sinais. [...] O contexto estreito do mosteiro e o seu conhecimento do mesmo é que são invocados pelo receptor. Isso lhe permitirá identificar o objeto pretendido pelo emissor, mesmo quando o sinal não tenha se tornado convencional. (p. 62-63, tradução minha) 
Para esse autor, os sistemas de sinais monásticos trabalham a partir de unidades significativas. $\mathrm{O}$ Monasterialis Indicia "apresenta um ar inerentemente desorganizado de bricolage. Pode se tomar qualquer coisa para transmitir informação. É firmemente enraizado nos sistemas culturais dos usuários, calcado nos outros conjuntos de classificação...” (p. 64, tradução minha). Ele avalia que, por sua qualidade aberta, esse sistema torna-se mais fácil de aprender e ampliar, mas perde em precisão.

O léxico dos sinais monásticos revela a especificidade do cotidiano voltado às práticas religiosas. Há nomes para os objetos utilizados na liturgia, bem como para as funções sociais desempenhadas pelos membros da comunidade. Martins ilustra:

Era uma comunidade hierarquizada, com o abade no vértice da pirâmide, abaixo dele o prior e, inferior a este, $\mathrm{o}$ soprior. O monge sacristão governava a vasta igreja e o mundo complexo dos códices litúrgicos. O cantor tinha às suas ordens o socãtor, o mestre dos noviços olhava pelo dócil rebanho de monges em botão, enquanto o celareiro e o socelareiro constituíam uma espécie de ministério da agricultura $[\ldots]$.

Tudo isso formava uma pequena república monacal, de tendência autárquica, com enfermeiros, esmoleres, cozinheiros, vestiairos, simples monges sem ofício especial, a não ser cantar as horas canónicas e trabalhar nos campos, e frades conversos de barba comprida [...], por isso mesmo chamados barbatos [...]. (1987, p. 550-551)

Como se percebe, os termos nos são pouco familiares. Desconhecendo o conceito nomeado pelo sinal, é difícil assimilar o seu sentido. Argumentando que o vocabulário dos sinais monásticos é pequeno, limitado a um contexto religioso restrito, Stokoe (1987) assume a posição de que, para os surdos que estivessem sendo educados nos conventos,

[...] um léxico limitado aos grãos, frutas, legumes, e outros alimentos permitidos àqueles que renunciaram ao mundo $\mathrm{e}$ seguiam a regra de São Bento literalmente o suficiente para se silenciarem a maior parte do tempo, um léxico ampliado com os nomes das vestimentas e outros artigos para uso litúrgico teria pouca função para um surdo educado, herdeiro de terras e administração secular e do governo, a condução de política externa e da sociedade aristocrática no geral. (p. 328, tradução minha)

Não tenho dúvida de que a língua de sinais dos mosteiros funcionava de maneira muito diferente das línguas de sinais primárias constituídas por surdos. Para começar, a base lingüística dos monges era a língua oral, e os sinais funcionavam como substitutos e complementos de sentidos subentendidos da oralidade. As listas monásticas arcaicas que examinamos são compostas prioritariamente por substantivos (nomes das coisas); contêm poucos pronomes, verbos, adjetivos e advérbios e não constam quaisquer preposições ou conjunções. Os sinais monásticos eram utilizados em situações de trabalho manual, em que o contexto garantiria a compreensão dos sentidos, para casos de ambigüidade.

Para os surdos, no entanto, a língua de sinais conquista status de língua, com uma gramática própria, relacionada à lógica dos movimentos e ao complemento da expressão facial e corporal que integram os sentidos. Eles desenvolvem coordenação, agilidade e fluência na interação lingüística. Desde que estejam reunidos durante um período prolongado de tempo, explica Plann (1997), podem reinventar o sistema, tantas vezes quanto for preciso, em lugares e tempos distintos.

\section{Os mosteiros e a acolhida aos surdos}

Um fator que certamente teria facilitado a migração dos sistemas sinalizados dos mosteiros para a educação dos surdos teria sido a presença de surdos nos mosteiros.

Existem documentos (bem como iluminuras) que registram que, no período monástico, os "tolos e inocentes" (loucos e deficientes mentais) que vagavam pelos feudos encontravam abrigo por poucos dias nos mosteiros. Eram alimentados, vestidos e tosados, e depois mandados adiante (Southworth, 1998). Não 
seria duvidoso que surdos se agrupassem nesses bandos, e nessa peregrinação conhecessem sinais monásticos que incorporariam ao seu repertório lingüístico, embora boa parte do léxico utilizado nos mosteiros, de cunho restrito às práticas religiosas, possivelmente não tivesse função para a interação cotidiana entre os surdos ou dos surdos com ouvintes, como vimos.

$\mathrm{Na}$ Idade Média, as atitudes do cristianismo em relação aos deficientes revelavam uma certa ambigüidade, gerando ora acolhida ora exclusão.

Por um lado, os doentes mentais e deficientes eram vistos como merecedores de castigos por pecados cometidos (ou pelo pecado original), pois o corpo marcado pelo estigma denotava a ação do mal; eram excluídos e isolados, vagando à margem da cidade. Por outro lado, os cristãos se preocupavam com a salvação da alma dos sofredores, por isso abrigavam-nos em mosteiros, quando abandonados pela família. Além disso, a virtude da caridade era valorizada e esperava-se dos cristãos a prática do amor ao próximo, concretizada no ato de dar esmolas aos miseráveis, entre os quais se encontravam cegos, "coxos", "dementes" e "mudos", como eram denominados os deficientes em textos da igreja antiga. (Reily, 2006)

Nessa segunda vertente enquadra-se a primeira menção da educação de surdos (na época denominados de mudos) registrada pelo Venerável Bede (c.737), que relata o milagre realizado por bispo John, um homem muito santo, que, à guisa de esmola, assumiu os cuidados de um mudo, o qual curou da mudez e de outras afecções do couro cabeludo, ensinando-lhe também as letras e a pronúncia de palavras e frases.

A despeito de anedotas como essa, não encontramos referências à presença de surdos das classes populares convivendo prolongadamente nos mosteiros beneditinos ou de outras ordens que praticavam o voto do silêncio. ${ }^{10}$ Coulton (1913), inclusive, ques-

${ }^{10}$ Chaves e Soler (apud Stokoe, 1987) consideram que não se pode generalizar que muitos filhos surdos da nobreza eram en- tiona, com forte argumentação e evidências documentais, o mito de que as escolas monásticas fossem abertas para quaisquer crianças pobres da comunidade do entorno do mosteiro (ouvintes ou surdas). Ele concede que as escolas monásticas certamente assumiram o ensino de todos os noviços e noviças, os oblatos (meninos monges) e todas as crianças prometidas para a Igreja. Nas raras ocasiões em que crianças foram admitidas nas escolas monásticas, eram filhos da nobreza, que "faziam das abadias de toda parte uma conveniência; alguns príncipes da realeza nasciam nelas" (p. 10, tradução minha). Foi somente a partir do Concílio de Trento ${ }^{11}$ que um sistema educacional monástico começou a assumir um papel de educação das crianças seculares, sem objetivo subjacente de formação para funções religiosas.

A força desses argumentos convence-me de que os sinais monásticos não migraram de forma tão linear dos mosteiros para a educação dos surdos quanto inicialmente se poderia supor. $\mathrm{O}$ que os registros dos primeiros educadores de surdos elucidam sobre o aproveitamento dos sinais monásticos e do alfabeto manual para o trabalho pedagógico com os surdos?

\section{Os primórdios da educação dos surdos}

\section{O monge beneditino Pedro Ponce de León (1520-} 1584) é reconhecido como o primeiro professor de surdos, tendo consolidado um trabalho de ensino de filhos surdos da aristocracia espanhola, ${ }^{12}$ no mosteiro

viados aos mosteiros para serem educados a partir de uma única instância registrada, que foi o trabalho desenvolvido pelo monge Pedro Ponce de León no Mosteiro de Valladolid em Oña em meados do século XVI.

${ }^{11} \mathrm{O}$ Concílio de Trento foi um concílio ecumênico organizado pelo Papa Paulo III e durou de 1545 a 1563, movido pela necessidade de a Igreja católica responder à Reforma Protestante (Cross \& Livingston, 1997).

${ }^{12}$ A incidência da surdez nas famílias da aristocracia e da realeza era muito alta, dada a prática dos casamentos consangüíneos como forma de manter as riquezas numa mesma camada social. 
beneditino de São Salvador em Oña, segundo Plann (1997), autora de um amplo estudo documental sobre a educação dos surdos na Espanha. Envolveu-se com a educação de surdos depois que foram enviados ao mosteiro de São Salvador os irmãos Francisco e Pedro Fernández de Velasco y Tovar, filhos de um casamento consangüíneo da nobreza espanhola. O casal teve pelo menos nove filhos, entre os quais quatro eram surdos: esses dois meninos e duas meninas, que foram enviadas a outros conventos. Entre eles provavelmente se havia desenvolvido uma sinalização caseira, que encontrou eco nos sinais beneditinos. O monge Ponce de León foi designado "anjo da guarda" dos meninos e foi aí que se deu o cruzamento histórico dos sinais monásticos com os sinais dos surdos.

O trabalho de Ponce de León foi reconhecido nacionalmente, havendo outros nobres com filhos surdos que deveriam ser educados para que pudessem assumir seu papel de herdeiros. Grande parte dos registros de sua metodologia perdeu-se, mas sobraram descrições de terceiros e uma folha manuscrita pelo próprio monge apresentando-a. Por esses fragmentos, Plann deduziu que os sinais beneditinos foram utilizados no início, complementados talvez pelos sinais caseiros dos irmãos Velasco. Ponce de León trabalhou com rótulos - nomes escritos pregados em tudo; o monge indicava as palavras escritas aos seus pupilos, associando a escrita à pronúncia da palavra. O alfabeto manual era utilizado - testemunhas oculares falam de um "alfabeto manual, um modo de soletrar no ar formando letras com os dedos" (Plann, 1997, p. 30); supõe-se que se tratava do alfabeto publicado por Yebra. Mesmo sendo de ordens distintas, pesquisadores como Daniels (1997) suspeitam que o franciscano Yebra e o beneditino Pedro Ponce de León tiveram ocasião de encontrar-se, pois ambos se relacionavam com a nobreza da corte espanhola. Ponce de León faleceu antes da publicação da obra de Yebra; no entanto, os alfabetos manuais manuscritos certamente circulavam nos mosteiros da Espanha.

Na página escrita de autoria de Ponce de León que supostamente faz parte de uma metodologia de ensino de surdos que foi perdida, há a sugestão de desenhar o alfabeto nas juntas dos dedos, uma idéia desenvolvida com bastante profundidade anos mais tarde por Dalgarno, em $1680 .{ }^{13}$

Na continuidade da narrativa sobre a transferência de saberes de um educador para o outro, Moores (1987) indica que houve uma ruptura entre as realizações do monge Ponce de León, que morreu em 1584, e Juan Pablo Bonet, autor de Reducción de las letras y arte de enseñar a hablar los mudos, publicado em 1620 e contendo um alfabeto digital muito similar ao que utilizamos hoje no Brasil. Bonet, um mercenário, começou a trabalhar em 1607 para a família de Juan de Velasco (cujo pai era irmão de Francisco e Pedro de Velasco, os alunos surdos já mencionados). Juan de Velasco morreu em 1613, e a viúva manteve Bonet como secretário do herdeiro Bernardino Fernandez de Velasco, de apenas quatro anos na época. Ela tinha mais dois filhos, sendo que Luis, de 3 anos, perdera a audição no ano anterior. Por intervenção real, Ramirez de Carrión, tutor especializado do Marquês de Priego, também surdo, foi requisitado a trabalhar com o jovem Luis. Carrión orientou o trabalho com o jovem Velasco de 1615 a 1619, quando retornou para servir o Marquês de Priego. Segundo Plann, Bonet tentou dar continuidade ao trabalho de Carrión, mas não obteve sucesso. Seu fracasso como professor não o impediu, no entanto, de publicar como sua uma metodologia de ensino de surdos no ano seguinte, o que lhe rendeu reconhecimento histórico internacional, tanto por ter mandado gravar representações das configurações manuais em água forte como pela divulgação de

${ }^{13}$ Em 1680, Dalgarno, por exemplo, criou um alfabeto bimanual mapeado na mão; ele propunha que os surdos calçassem uma luva com letras escritas, para que pudessem escrever rapidamente, apontando as letras na mão (Cram \& Maat, 2001). As vogais ficavam nas pontas dos dedos. Didático, o método despertou enorme interesse entre filósofos, mas o sistema bimanual não se mostrou funcional e não foi assimilado na educação de surdos no Reino Unido; lá, atualmente, os surdos utilizam um alfabeto bimanual, remanescente de uma versão monástica das ilhas britânicas, publicado por Wallis (1653). 
uma metodologia fonética de alfabetização (que já estaria em uso entre educadores de ouvintes, explica Plann). Esse sistema solucionava o problema de ensinar os nomes das letras ("Aleph" para "A", por exemplo), diminuindo o alfabeto para 21 sons, e valorizava a representação sonora de cada elemento gráfico.

Para Plann, o período de 1615 a 1619 foi demasiadamente curto para que Bonet construísse a metodologia de trabalho que publicou em 1620. A autora supõe que ele acompanhou o trabalho de Carrión na educação de Luis de Velasco, e dessa forma teve acesso ao alfabeto manual e à metodologia de ensino. Alguns autores propõem que Bonet pode ter tido acesso ao manuscrito perdido de Pedro Ponce de León, por intermédio da família Velasco, mas, para Plann, as duas metodologias são divergentes demais para sustentar tal hipótese. Tanto Bonet quanto Carrión enfatizavam uma pedagogia ouvinte, tendo como objetivo a fala, ao passo que Ponce de León trabalhou com sinais para chegar na escrita, enfrentando a articulação da fala como etapa final.

\section{Como a língua de sinais e o alfabeto manual chegaram a l'Épée}

O abade Charles Michel de l'Épée ${ }^{14}$ é destacado na história da educação do surdo por ter reconhecido a necessidade de usar sinais como ponto de partida para o ensino do surdo, segundo Rée (2000). O próprio abade relatou como se envolveu com esse trabalho. Duas irmãs gêmeas surdas estavam sendo educadas pelo padre Vanin, que veio a falecer. L'Épée propôs-se a dar continuidade ao ensino em 1760 por temer que, sem professor, elas morreriam na ignorân-

${ }^{14}$ Nota-se que no século XVIII o movimento monástico já não estava em vigor nos moldes de Idade Média. O título de abade não significava que l'Épée chefiava uma abadia nem que morava num mosteiro. Assim, diferentemente de Ponce de León, que conhecia intimamente os sinais beneditinos, l'Épée teve seu contato com sinais por intermédio dos surdos e foi criando mímicas em negociação com seus alunos. cia de sua religião; decidiu mudar a metodologia utilizada anteriormente, que era o uso de gravuras para ensinar o cristianismo, pois entendeu que a compreensão se restringiria ao significado literal, físico da imagem, e que o sentido mais profundo da fé seria impossível de transmitir apenas por figuras visuais. Não tinha nenhum conhecimento sobre educação de surdos e resolveu ensinar linguagem pelos olhos, em vez de pelos ouvidos, apontando os objetos com uma mão e escrevendo o nome correspondente na pedra (lousa) com a outra. Lembrou-se de um alfabeto bimanual que utilizara na escola, para poder comunicar-se com os colegas sem ser descoberto pelo mestre. (Não sabemos qual alfabeto esse teria sido, mas defendemos a hipótese de que tenha sido uma versão monástica.) Com esse método associacionista, segundo l'Épée, logo as meninas estavam lendo e escrevendo os nomes das coisas. No entanto, esse sistema não permitia maiores avanços, porque não contemplava nenhuma gramática, nem sentidos abstratos, essenciais para o ensino religioso, restringindo-se à nomeação de objetos presentes, visíveis, perceptíveis pelos sentidos. O abade chegara a um impasse.

Num momento de insight, porém, deu-se conta de que as meninas já deveriam possuir um sistema gramatical, pois elas se comunicavam entre si com muita fluência. L'Épée concluiu que deveria aprender a gramática com os sinais de suas alunas para então lapidá-los, desenvolvendo um método para aproximar os sinais à língua francesa. O número de alunos aumentou, e a escola, filantrópica, não fechava as portas a ninguém. Segundo Rée (2000), os surdos congregaram-se em torno do espaço educacional oferecido pelo abade, trazendo suas formas linguiísticas consigo, e também aprendendo com os surdos da instituição, que certamente já estavam constituindo uma forma híbrida e funcional baseada nas necessidades da prática e influenciada certamente, quando convinha, pelos ensinamentos do sistema metódico de l'Épée (s.d.).

O abade de l'Epée teve contato com o alfabeto manual espanhol provavelmente em 1764. O próprio abade conta no texto L'art d'enseigner a parler aux 
sourds-muets de naissance que estava dando uma aula pública quando um sujeito se aproximou e lhe vendeu um livro. Abrindo-o aleatoriamente, viu "o alfabeto manual dos espanhóis, bem gravado em água forte" (l’Épée, s.d., p. 66); então comprou o livro. Espantou-se ao ver que a obra se chamava Arte para enseñar a hablar a los mudos. L'Épée resolveu aprender espanhol para conseguir ler o texto. Segundo Rée, o abade percebeu que as configurações unimanuais eram mais eficientes, e abandonou seu velho sistema bimanual. Pouco tempo depois, uma das pessoas que assistia a suas aulas públicas lhe avisou que havia na biblioteca de um amigo uma obra em latim sobre o mesmo assunto, e foi assim, então, que ele tomou contato com a obra do médico suíço Amman, Dissertatio de loquelâ surdorum et mutorum, que propunha uma pedagogia eminentemente oralista.

$\mathrm{O}$ abade afirmava que a única maneira de chegar ao espírito dos surdos era pela via "dos mesmos sinais pelos quais a natureza os inspira". Ensinar a ler em voz alta, com base na metodologia de Amman, foi estabelecido como etapa posterior.

Quando o abade de l'Épée sistematizou os sinais ao constituir os sinais metódicos, ele apropriou-se de muitos sinais que os surdos já utilizavam, criou outros tantos e acrescentou movimentos aos elementos lexicais para demarcar funções gramaticais francesas no conjunto de sinais que considerava fundamentais para a comunicação e a aprendizagem das lições. No contexto das aulas e dos exercícios públicos, o autor indica que os sinais eram dominados a tal ponto que complexas questões metafísicas eram propostas por meio dos sinais metódicos e os alunos adiantados eram capazes de responder corretamente em francês, às vezes também em latim.

Outro mérito que cabe ao abade de l'Épée é o do reconhecimento público das fontes que utilizou para fundamentar sua metodologia, bem como a divulgação gratuita do conhecimento produzido em Paris. Diferentemente de seus antecessores e de seus contemporâneos, como Jacó Rodrigues Pereira (17151780), em Paris, Thomas Braidwood (1715-1806) em Edimburgo e Samuel Heinecke (1729-1790) em Vie- na, que escondiam o segredo de seu sucesso de ensino de surdos, o abade de l'Épée fez questão de dar crédito a quem contribuiu no campo de conhecimento. Convidava os interessados a visitarem sua instituição, para que conhecessem sua metodologia e semeassem suas idéias em outros centros, numa obra verdadeiramente missionária. Esse é o motivo por que os Estados Unidos, e posteriormente o Brasil, herdaram o sistema francês de sinais, em vez da metodologia oralista inglesa ou alemã.

$\mathrm{O}$ abade conseguiu convencer seus contemporâneos quanto ao sucesso do seu método, mas os mestres que o seguiram perceberam que os alunos haviam automatizado respostas sem compreender as perguntas. Verificaram que os sinais metódicos ensinados pelo abade de l'Épée não atravessavam para as interações cotidianas: os surdos utilizavam-se de outra língua nas interações pessoais. A tentativa de fazer vingar um língua artificial podia funcionar em contextos rígidos do ensino religioso para responder a questões fechadas, mas jamais atenderia às necessidades do cotidiano.

\section{Palavras de conclusão}

Historicamente, a escolarização do surdo esteve estreitamente vinculada à tradição educacional estabelecida desde a época da Igreja monástica, tanto pela questão dos sinais criados para a comunicação silenciosa como pelo ministério da Igreja católica dirigida aos surdos da congregação, registrados desde a época do Venerável Bede (1965). Daí o interesse em conhecer documentos antigos como os sinais monásticos e os registros de educadores religiosos pioneiros do século XVIII que descreveram os eixos curriculares, a metodologia de ensino e a introdução de preceitos religiosos no processo educacional dos surdos. Esses registros ajudam a compreender por que os educadores católicos participaram do movimento de legitimação da língua de sinais na prática pedagógica, enquanto outros educadores de surdos na Europa daquele período investiram fervorosamente no método oralista. Seguindo uma tradição consagrada pelos primeiros 
apóstolos e pais da Igreja cristã, o abade de l’Épée legou-nos uma série de documentos publicados, contendo correspondência, pareceres, programas e metodologia pedagógica, que nos auxiliam a preencher as lacunas desse interessantíssimo capítulo da educação especial, alguns dos quais podem ser acessados na Biblioteca Nacional da França (http://gallica.bnf.fr/).

O estudo realizado demonstrou que a história da educação dos surdos não foi linear com gradativos avanços, como muitos textos fazem supor. Pelo contrário, houve ensaios, experimentos e reinvenções, muitas vezes sem seguimento. Metodologias foram criadas e perdidas ou abandonadas; em algumas ocasiões, podem ter sido apropriadas indevidamente. Concluímos este estudo afirmando, com base no exposto, que os usuários dos alfabetos manuais hoje utilizados pelas comunidades surdas (como a brasileira e a norte-americana) que seguiram a tradição espanhola e francesa de educação de surdos seguramente devem ao movimento monástico a invenção desse valioso instrumento de escrita no ar. Mas, depois de mergulhar na análise das listas monásticas e refletir com os comentaristas das listagens, somos obrigados a concordar com Stokoe (1987): a origem das línguas de sinais dos surdos não se encontra nos sinais monásticos. Alguns sinais podem ter parentesco, mas o léxico não é suficientemente partilhado e, principalmente, a sintaxe não é equivalente.

A contribuição do movimento monástico foi outra: consolidou uma concepção do silêncio que seguramente mobilizou os pioneiros, como o monge beneditino Pedro Ponce de León e o abade Charles Michel de l'Épée, a entender que a comunicação pelos gestos constituía uma forma válida e muito eficaz de significação.

Outro aspecto que merece ser destacado é o papel essencial dos religiosos na prática do registro. Nesse sentido, o abade de l'Épée seguiu a tradição dos padres católicos, legando-nos documentos preciosos que atestam os resultados de suas experiências, os exercícios pedagógicos que propunha e seus princípios de ensino, revelando seu compromisso e sua dedicação no trabalho de educação dos surdos.
Se a língua de sinais não veio dos mosteiros, de onde veio? Recria-se cada vez que um grupo de surdos convive por um tempo prolongado? A proposta pioneira de Ponce de León, reinventada em outro espaço e tempo por l'Épée, promoveu o agrupamento de uma comunidade de surdos, o que foi fundamental para a consolidação da língua de sinais como prática cultural. Um dos fatores cruciais para o estabelecimento do sistema de sinais como língua foi o convívio de um grupo de surdos no Mosteiro de Oña e depois no Instituto de Surdos Mudos de Paris; os novatos que chegavam apropriavam-se da língua convencionalizada e tornavamse cidadãos de uma comunidade pela primeira vez.

Como confirmação de que os sinais monásticos não se extinguiram totalmente, finalizo o presente texto com um segmento de uma missiva que nos foi enviada por e-mail há cerca de um ano por um abade cisterciense, a respeito da prática dos sinais nos dias de hoje, no seu mosteiro no Paraná.

Espero não lhe causar decepção mas nossa comunicação por sinais caiu com o Concílio Vat. II, pois a partir daí o silêncio absoluto tornou-se uma necessidade muito mais interiorizada, isto é, a Ordem Cisterciense da Estrita Observância continuou valorizando o silêncio como algo que brota de cada indivíduo pelo grau de intimidade que cada um possui com Deus.

O silêncio hoje nos mosteiros trapistas não é um regulamento nem voto mas um respeito que cada monge nutre pelo mistério do outro. Nos esforçamos para manter um estado de oração constante, a memoria Dei, e por isso um ambiente de silêncio propicia maior facilidade para atingir a lembrança contínua de Deus. Temos diálogos comunitários, partilha de alguma coisa a respeito do bem estar comunitário, aulas, conferências onde temos oportunidade de expressar nosso pensamento, explicação de trabalhos e mesmo alguma comunicação muito fraterna e espontânea. Assim conversamos entre nós mas sempre resguardando o ambiente contemplativo, de maneira que cada monge possa com toda tranqüilidade passar todo o seu dia em profunda união com Deus.

Temos em nossa biblioteca um livro com as senhas usadas anos atrás, o que causa curiosidade para os novos. Conser- 
vamos uns pouquíssimos sinais para nos comunicarmos caso necessário em momentos em que não podemos falar verbalmente. Conversamos relativamente bem pouco entre nós mas nosso silêncio não é absoluto.

\section{Referências bibliográficas}

BAINTON, Roland H. Christendom: a short history of Christianity and its impact on Western Civilization. New York: Harper and Row Publishers, 1966.

BANHAM, Debby (Org.). Monasteriales Indicia. The AngloSaxon monastic sign language. Pinner, Reino Unido: Anglo-Saxon Books, 1991.

BARLEY, Nigel. Two Anglo-Saxon sign systems compared. In: UMIKER-SEBEOK, Jean; SEBEOK, Thomas A. (Orgs.). Monastic sign languages. New York: Mouton de Gruyter, 1987. p. 53-65. BEDE, The Venerable (c. 731). The ecclesiastical history of the English nation \& the lives of St. Cuthbert \& the Abbots. Dutton, New York: Everyman's Library, 1965.

BENTLEY, Samuel. A table of signs used during the ours of silence by the sisters in the Monastery of Sion. In: UMIKER-SEBEOK, Jean; SEBEOK, Thomas A. (Orgs.). Monastic sign languages. New York: Mouton de Gruyter, 1987. p. 487-494.

CHAVES, Teresa; SOLAR, Jorge. Pedro Ponce de León, first teacher of the deaf. Sign Language Studies, n. 5, p. 48-63, 1974. COULTON, G. G. Monastic schools in the middle ages. Medieval studies, London: Simkin, Marshall, Hamilton, Kent \& Co., Ltd, n. X, p. 17-44, 1913.

CRAM, David; MAAT, Jaap. George Dalgarno on Universal Language. The art of signs (1661), The deaf and dumb man's tutor (1680) and the Unpublished Papers. New York: Oxford University Press, 2001.

CROSS, F. L.; LIVINGSTON, E. A. (Orgs.). The Oxford dictionary of the Christian Church. 3. ed. Oxford: Oxford University Press, 1997. DANIELS, Marilyn. Benedictine roots in the development of deaf education: listening with the heart. Westport, Connecticut: Bergin \& Garvey, 1997.

DU BOIS, Louis François. Vocabulaire des Signes Pratiqués dans l'Ordre de Cîteaux. In: UMIKER-SEBEOK, Jean; SEBEOK, Thomas A. (Orgs.). Monastic sign languages. New York: Mouton de Gruyter, 1987. p. 601-613.

ECO, Umberto. A busca da língua perfeita na cultura européia. Trad. Antonio Angonese. Bauru: EDUSC, 2001.
ERIKSSON, Per. The history of deaf people. A source book. Trad. James Schmale. Örebro, Suécia: Daufr Deaf History, 1993. GRAHAM, Hugh. The early Irish monastic schools: a study of Ireland's contribution to medieval culture. Dublin: The Talbot Press, 1923. HUTT, Clelia. Étude d'un corpus: dictionnaire du langage gestuel chez les Trappistes. Langages, v. 10, p. 107-118, jun. 1968.

L'ÉPÉE, Charles Michel de. L'art d'enseigner a parler aux sourdsmuets de naissance: augmenté de notes explicatives et d'un avantpropos par M. L'Abbé Sicard. Paris: J.G. Dentu, s.d.

MALLERY, Garrick. Sign language among North American Indians. New York: Dover Publications, 2001.

MARTINS, Mário. Livros de sinais dos cistercienses portugueses. In: UMIKER-SEBEOK, Jean; SEBEOK, Thomas A. (Orgs.). Monastic sign languages. New York: Mouton de Gruyter, 1987. p. 533-599.

MOORES, Donald E. Educating the deaf: psychology, principles and practices. Boston: Houghton Mifflin Company, 1987.

O CONBHUIDHE, Colmcille. The Cistercian abbeys of Tipperary. Editado por Finbarr Donovan. Dublin: Four Courts Press, 1999. PENNA, Mario. I "Signa Loquendi" Cisterciensi in um Codice Della Biblioteca Nacional di Madrid. In: UMIKER-SEBEOK, Jean; SEBEOK, Thomas A. (Orgs.). Monastic sign languages. New York: Mouton de Gruyter, 1987. p. 495-531.

PLANN, Susan. A silent minority: deaf education in Spain, 15501835. Berkeley: University of California Press, 1997.

RÉE, Jonathan. I see a voice: deafness, language and the senses - a philosophical history. New York: Henry Holt and Company, 2000. REILY, Duncan Alexander. Ministérios femininos em perspectiva histórica. 2. ed. São Bernardo do Campo: Editeo e CEBEP, 1997. Lucia: it occurred to me that a few facts about fairly early Christianity might be helpful to you in your understanding Monasticism. Campinas, s.ed., 2003. [Documento manuscrito, dezembro.]

REILY, Lucia. Escola inclusiva: linguagem e mediação. Campinas: Papirus, 2004.

Representações de deficiência em pinturas de temática religiosa: questões metodológicas. In: JESUS, Denise Meyrelles de; BAPTISTA, Cláudio Roberto; VICTOR, Sonia Lopes (Orgs.). Pesquisa e educação especial: mapeando produções. Vitória: EDUFES, 2006. p. 341-359.

REILY, Lucia; REILY, Duncan Alexander. A constituição da língua de sinais e do alfabeto manual na igreja monástica. In: REUNIÃO ANUAL DA ANPEd, 26., Caxambu,23. Anais... Caxambu: ANPEd, 2003. 1 CD-ROM. 
SÃO BASÍLIO MAGNO (c. 370). As regras monásticas. Trad. Ir. Hildegardis Pasch e Ir. Helena Nagem Assad. Petrópolis: Vozes, 1983.

SÃO BENTO (c. 500). A Regra de São Bento. Trad. D. Basílio Penido. Petrópolis: Vozes, 1993.

SOFIATO, Cássia G. O desafio da representação pictórica da língua de sinais brasileira. Dissertação (Mestrado) - Instituto de Artes, Universidade Estadual de Campinas, 2005.

SOUTHWORTH, John. Fools and jesters at the English court. Londres: Sutton Publishing, 1998.

STOKOE, William C. Sign language and the monastic use of lexical gestures. In: UMIKER-SEBEOK, Jean; SEBEOK, Thomas A. (Orgs.). Monastic sign languages. New York: Mouton de Gruyter, 1987. p. 323-338.

TOMKINS, William. Indian sign language. New York: Dover Publications, 1969.

UMIKER-SEBEOK, Jean; SEBEOK, Thomas A. (Orgs.). Monastic sign languages. New York: Mouton de Gruyter, 1987.

VAN RIJNBERK, Gérard. Le langage par signes chez les moines. In: UMIKER-SEMEOK, Jean; SEBEOK, Thomas A. (Orgs.). Monastic sign languages. New York: Mouton de Gruyter, 1987. p. 13-25.

VYGOTSKY, L. S. (1930-1934). A formação social da mente. Trad. José Cipolla Neto, Luis Silveira Menna Barreto e Solange Castro Afeche. São Paulo: Martins Fontes, 1988.

WALKER, Williston (1918). A history of the Christian Church. 4. ed. New York: Charles Scribner's Sons, 1985. Consultores: Norris, R. A.; Lotz, D.W.; Handy, R.T.
WALLIS, John. De loquela, sive sonorum formatione, tractatus grammatico-physicus. Prefácio. In: Grammatica linguae anglicanae. S.1.: Oxford, 1653.

WERTSCH, James. Voices of the mind: a sociocultural approach to mediated action. Londres: Harvester Wheatsheaf, 1991.

LUCIA REILY, doutora em psicologia escolar pelo Instituto de Psicologia da Universidade de São Paulo, é arte-educadora no Centro de Estudos e Pesquisas em Reabilitação Prof. Dr. Gabriel Porto, vinculado à Faculdade de Ciências Médicas da Universidade Estadual de Campinas. Publicações recentes: Escola inclusiva: linguagem e mediação (Campinas: Papirus, 2004); Armazém de imagens: ensaio sobre a produção artística de pessoas com deficiência (Campinas: Papirus, 2001); As imagens: o lúdico e o absurdo no ensino de arte para pré-escolares surdos (In: SILVA, Ivani R. et al. Cidadania, surdez e linguagem: desafios e realidades. São Paulo: Plexus, 2003. p. 161-192); Representações de deficiência em pinturas de temática religiosa: questões metodológicas (In: JESUS, Denise Meyrelles de; BAPTISTA, Cláudio Roberto; VICTOR, Sonia Lopes (Orgs.). Pesquisa e educação especial: mapeando produções (Vitória: EDUFES, 2006. p.341359). Pesquisas em desenvolvimento: "A língua de sinais nos mosteiros e os primórdios da educação do surdo" e "Retratos de deficiência e doença mental: intersecções entre a história da educação especial e a história da arte”. E-mail: lureily@ terra.com.br

Recebido em novembro de 2005 Aprovado em julho de 2006 